\title{
Basic Notions of Information Structure
}

\author{
Manfred Krifka \\ Humboldt Universität zu Berlin \\ and Zentrum für Allgemeine Sprachwissenschaft, Berlin
}

\begin{abstract}
This article takes stock of the basic notions of Information Structure (IS). It first provides a general characterization of IS - following Chafe (1976) — within a communicative model of Common Ground (CG), which distinguishes between CG content and CG management. IS is concerned with those features of language that concern the local CG. Second, this paper defines and discusses the notions of Focus (as indicating alternatives) and its various uses, Givenness (as indicating that a denotation is already present in the CG), and Topic (as specifying what a statement is about). It also proposes a new notion, Delimitation, which comprises contrastive topics and frame setters, and indicates that the current conversational move does not entirely satisfy the local communicative needs. It also points out that rhetorical structuring partly belongs to IS.
\end{abstract}

Keywords: Information Structure, Focus, Topic, Givenness, Contrast

\section{Introduction}

The basic notions of Information Structure (IS), such as Focus, Topic and Givenness, are not simple observational terms. As scientific notions, they are rooted in theory, in this case, in theories of how communication works. Hence this paper necessarily will make certain theoretical assumptions, without going into great details. I will motivate the selection of IS notions in the tradition of Chafe (1976) who talked about IS as a phenomenon of information packaging that responds to the immediate communicative needs of interlocutors. I do this within the model of communication as continuous change of the common

Interdisciplinary Studies on Information Structure 6 (2007): 13-55

Féry, C., G. Fanselow and M. Krifka (eds.):

The Notions of Information Structure

(C)2007 Manfred Krifka 
ground (CG), where it will be crucial to distinguish between $\mathrm{CG}$ content and what I will call CG management.

IS is a vast topic of research that has been pursued within different theoretical frameworks, and has produced numerous empirical insights. This short paper cannot conclusively argue for its choices in detail, vis-à-vis other theoretical options, or attempt to motivate them by considering phenomena in a wider range of languages. In spite of this, I hope that a coherent and attractive theoretical landscape emerges for IS research.

\section{Preliminaries}

\subsection{What is Information Structure?}

In his seminal 1976 paper on notions of IS, Chafe introduced the notion of packaging of the information conveyed in an utterance that, to my mind, still provides useful guidance for our understanding of IS. Chafe wisely restricted his notion of IS to those aspects that respond to the temporary state of the addressee's mind, thus excluding several other aspects of messages, like reference to long-term background knowledge, choice of language or level of politeness that otherwise could be understood as packaging as well.

One problem with Chafe's approach is that there are aspects of optimization of the message that, on the one hand, respond to the temporary state of the addressee's mind, but on the other also affect the message itself, and hence cannot be treated as pure packaging. For example, Focus, as expressed by sentence accent in English, can be used for information packaging, as in answers to questions, cf. (1), but can also lead to truth-conditional differences, as when associated with focus-sensitive particles like only, cf. (2).

(1) a. A: What did John show Mary?

B: John showed Mary [the PICtures $]_{F}$. 

b. A: Who did John show the pictures?
B: John showed $[\text { MAry }]_{F}$ the pictures.

(2) a. John only showed Mary [the PICtures $]_{\mathrm{F}}$.

b. John only showed $[\text { MAry }]_{\mathrm{F}}$ the pictures.

The truth conditions of B's answers in (1) arguably are the same, whereas the truth conditions of

(2) differ. One and the same linguistic device, sentence accent, can be used for packaging as well as for constructing the content. There are two possible ways of dealing with this multiple use of features such as accent: One is to assume that the two uses of the same feature are essentially unrelated, just as the uses of accent in English to express focus and to distinguish words such as REcord and reCORD. The other is to assume that the feature is to be interpreted in a particular way that makes sense for the purposes of information packaging and of building information content. For methodological reasons the second alternative appears to be more attractive: If it can be shown that one and the same interpretation of a feature has multiple uses, then this option should favored over the assumption of multiple interpretations. We will see that focus indeed can be interpreted in this way.

\subsection{Common Ground: Content and management}

If we are to talk about communication as transfer of information and its optimization relative to the temporary needs of interlocutors, it is useful to adopt a model of information exchange that makes use of the notion of Common Ground. The original notion of CG (cf. Stalnaker 1974, Karttunen 1974, Lewis 1979) saw it as a way to model the information that is mutually known to be shared and continuously modified in communication. This allowed for a promising way of modeling the distinction between presuppositions, as requirements 
for the input $C G$, and assertions or the proffered content, as the proposed change in the output CG. This distinction is relevant for information packaging, as the CG changes continuously, and information has to be packaged in correspondence with the $\mathrm{CG}$ at the point at which it is uttered. For example, it can be explained why (3.a) is fine but (b) is odd: In (a), the first clause introduces the information that the speaker has a cat, to which the presupposition of the second clause appeals. This contrasts with (3.b), as the second sentence introduces the information that the speaker has a cat which is already present in the input CG at this point (cf. van der Sandt 1988).

(3) a. I have a cat, and I had to bring my cat to the vet.

b. \# I had to bring my cat to the vet, and I have a cat.

Already when the notion of CG was introduced, it was pointed out that speakers could change CG by accommodation of presupposition. That is, uncontroversial facts could be added implicitly to the $\mathrm{CG}$ by requiring the input $\mathrm{CG}$ to be of a certain kind. This is why (4.a) is good but (b) is bad:

(4) a. I had to bring my cat to the vet because it was sick.

b. I had to bring my gorilla to the vet because it was sick.

The notion of CG had first been applied to factual information, but it soon got extended to discourse referents (in particular, by Kamp 1981 and Heim 1982). That is, CG does not only consist of a set of propositions that is presumed to be mutually accepted (or the conjunction of this set, one proposition), but also of a set of entities that have been introduced into the CG before. Such entities can be explicitly introduced, e.g. by an indefinite NP, or they can be accommodated, as in (4.a). They can be taken up by pronouns, as in the second clause of (4.a), or 
by definite NPs, which express requirements to the input CG. The choice of anaphoric expression depends on the recency of the antecedent, again a notion that falls squarely within Chafe's notion of packaging.

The properties of CG mentioned so far all had to do with the truthconditional information in the $\mathrm{CG}$, so we can subsume them under the heading of CG content. But any ecologically valid notion of CG must also contain information about the manifest communicative interests and goals of the participants. For example, questions typically do not add factual information to the common ground, but indicate informational needs on the side of one participant that should be satisfied by a conversational move of the other. I propose to call this dimension of the common ground CG management, as it is concerned with the way the CG content should develop. Just as CG content, CG management is supposed to be shared, with the understanding that the responsibility for it may be asymmetrically distributed among participants. There is a wide variety of studies that can be captured under the notion of CG management, some formal such as Merin (1994) or Groenendijk (1999), some less formal such as Clark (1996) and studies of Conversational Analysis such as Hutchby \& Wooffitt (1988). The distinction between CG content and CG management is important for our purposes, as we can associate those aspects of IS that have truth-conditional impact with CG content, and those which relate to the pragmatic use of expressions with CG management.

\subsection{Expressions and what they stand for}

Before we discuss specific notions of IS, I would like to mention a terminological problem. We often find that the distinction between an expression and what it stands for, its denotatum, is not made. For example, in a sentence like (5), the expression as for the beans, or the beans, may be called the 'topic' of the sentence, but also the beans themselves are called its 'topic' sometimes. 
(5) As for the beans, John ate them.

For some reason, this confusion of expression and meaning occurs particularly often for IS notions. For notions like 'subject', 'predicate' or 'direct object' it does not arise; no one would claim that John the person is the grammatical subject of (5), it is John the noun phrase. The imprecision of IS terms can be endured if one is aware of it. But in any instance in which it is relevant, it is important to make the intended interpretation clear. For example, we can speak of (as for) the beans as the 'topic constituent' of the sentence, or as a 'topic expression', and of the beans that it refers to, or of the discourse referents anchored to them, as the 'topic referents' or 'topic denotation'.

\section{Focus}

\subsection{What is Focus?}

The most successful understanding of focus, to my mind, is the following definition, which will presently be rendered more precise.

\section{(6) Focus indicates the presence of alternatives that are relevant for the} interpretation of linguistic expressions.

This is the central claim of Alternative Semantics (Rooth 1985, 1992). ${ }^{1}$ The rather general definition does not say anything about how focus is marked; in fact it is compatible with different markings. However, it demands that we should only use terms like 'focus marking' or 'focus construction' to indicate that alternatives play a role in interpretation. It might well be that different ways of focus marking signal different ways of how alternatives are exploited; e.g. focus marking by cleft sentences often signals an exhaustive interpretation that in-

\footnotetext{
1 But it is not necessarily tied to the precise representation of focus that this theory proposes.
} 
situ focus lacks. We can then speak about subtypes of focus, such as cleft focus and in-situ-focus that may employ the alternatives in more specific ways. Also, (6) allows for languages to differ in the ways they mark focus and in the specific interpretational effects of focus. This is in no way different from other linguistic categories, such as case or gender. But it seems reasonable, and consistent with current uses of the term, to use 'focus' exactly in those cases that satisfy (6). ${ }^{2}$ The following sections will show that all current uses of the term can be subsumed under (6).

\subsection{Expression focus and denotation focus}

Definition (6) is silent about the nature of the alternatives that are relevant for interpretation. In fact, the alternatives may be alternatives of form or of denotation. This suggests the following way to make (6) more precise:
A property $F$ of an expression $\alpha$ is a Focus property iff $F$ signals
(a) that alternatives of (parts of) the expression $\alpha$ or
(b) alternatives of the denotation of (parts of) $\alpha$ are relevant for the interpretation of $\alpha$.

I call the first case, (a), expression focus. The expression alternatives can affect a variety of aspects, like choice of words and pronunciation, and they do not even have to involve constituents or meaningful units. Focus on expressions is typically used for corrections, and often, but not necessarily, comes with an overt negation (cf. Horn 1985 on metalinguistic negation). Two examples:

$$
\text { Grandpa didn't [kick the BUcket } \left.]_{\mathrm{F}} \text {, he [passed aWAY }\right]_{\mathrm{F}} \text {. }
$$

2 It should be pointed out that there are cases in which alternatives that are not indicated by focus play a role. For example, the standard theory of scalar implicatures assumes that they arise due to alternatives to an expression ordered by a Horn scale, and these alternatives do not have to be focused. For instance, John or Mary will come implicates that not both of them will, as or has and as its alternative, but clearly, or does not have to be focused. 
(9) A: They live in BERlin.

B: They live in $[\text { BerLIN }]_{F}$ !

In (8) the relevant alternatives of both foci are the expressions \{kick the bucket, pass away\}. It cannot be their denotations, as they are identical, the property DIE. The expressions differ, among other things, in their connotations, which is the feature in which they are contrasted here, so what is contrasted cannot just be their denotation. In (9) the relevant alternatives are the expressions \{BERlin, BerLIN\} that only differ in their accent and speaker B corrects speaker A by supplying the form that B thinks has the right accent structure.

Expression focus is typically marked in-situ, not by clefts or other types of movement. It can focus on constituents below the word level, and it can be deeply embedded within a sentence. This follows from the assumption that expression focus affects surface representations of linguistic objects. The typical use of expression focus is the rejection of a string $\left[\alpha_{1} \ldots \alpha_{\mathrm{i}, \mathrm{F}} \ldots \alpha_{\mathrm{n}}\right]$ in favor of a string $\left[\alpha_{1} \ldots \alpha_{\mathrm{I}, \mathrm{F}}{ }^{\prime} \ldots \alpha_{\mathrm{n}}\right]$, where focus identifies the substring to be replaced and its replacement.

I will call the second case, (b), denotation focus. Here, the relevant alternatives are construed on the level of denotations, leading to alternative denotations of complex expressions. Denotation focus on an expression $\alpha$ with a meaning $\|\alpha\|$ leads to the assumption of a set of alternative meanings that play a role in the interpretation of the constituent in which $\alpha$ occurs. The alternative denotations have to be comparable to the denotation of the expression in focus, that is, they have to be of the same type, and often also of the same ontological sort (e.g., persons or times), and they can be more narrowly restricted by the context of utterance.

In the following, I will concentrate on denotation focus, which is certainly more important in communication. 


\subsection{Semantic vs. pragmatic uses of focus: CG content vs. CG management}

We now turn to the notion of interpretation of the linguistic expression $\alpha$ that figured in definition (7). It is useful to explicate this notion within the general theory of Common Ground (CG) introduced in section 2.2, where we also introduced the distinction between CG content and CG management. This differentiation is useful to distinguish between two quite different uses of focus: So-called pragmatic uses of focus relate to the common communicative goals of the participants, the CG management, whereas so-called semantic uses of focus relate to the factual information, the CG content.

The pragmatic use of focus does not have an immediate influence on truth conditions, but it helps in guiding the direction into which communication should develop, and it also aids in building the cognitive representations that are to be constructed by the interlocutors. Failing to select the right focus typically results in incoherent communication. The semantic use of focus, on the other hand, affects the truth-conditional content of the CG. Failing to set focus right will result in transmitting unintended factual information. The two uses of focus cannot always be neatly separated, but there are prototypical cases that clearly belong to one or to the other category, to which we now turn.

\subsection{Pragmatic uses of focus}

The classical pragmatic use of focus is to highlight the part of an answer that corresponds to the wh-part of a constituent question (Paul 1880). This can be captured in a straightforward way within our model of CG change.

A question changes the current $\mathrm{CG}$ in such a way as to indicate the communicative goal of the questioner. Following Hamblin (1973) we can model this effect by interpreting a question as a set of propositions, each being the denotation of a congruent answer. 
(10) A: Who stole the cookie? Hamblin meaning: $\{$ STOLE(COOKIE)(x) $\mid \mathrm{x} \in$ PERSON $\}$

The answer identifies one of these propositions and adds it to the CG content; this is the job of the 'ordinary meaning' in Alternative Semantics. Focus induces alternatives that correspond to the Hamblin meaning of questions; in the theory of Rooth (1992), the alternative set is a superset of the question set:

(11) B: $[\text { PEter }]_{\mathrm{F}}$ stole the cookie.

Ordinary meaning of the answer: \{STOLE(COOKIE)(PETER)\}

Focus-induced alternatives: $\left\{\operatorname{STOLE}(\operatorname{COOKIE})(\mathrm{x}) \mid \mathrm{x} \in \mathrm{ENTITY}^{3}\right\}$

The formation of the question, as well as the construction of the focus-induced alternatives of the answers, clearly belongs to CG management, not to CG content. The question specifies the way in which the CG should develop in the immediate future; the answer relates an expression to the immediately preceding context. Obviously, focus in answers is an information-packaging device in the sense of Chafe, as it corresponds to the current CG, and the formation of questions, as a device of CG management, can be seen as part of information packaging as well.

We might ask at this point why there is marking of question-answer congruence in the first place. Its raison d'être most likely is that it allows to accommodate the meaning of the questions that are not overtly expressed. That is, it allows to accommodate CG management. For example, the accent structure in (12) can be understood in such a way that the second clause leads to the accommodation of a question, what did you do first.

3 The focus is not restricted to PERSON, different from the question (10), in which the whword who enforces this restriction. 
(12) I built a St. Martin's lantern with my kids. First, I [built the BOdy of the lantern with some CARDboard paper $]_{\mathrm{F}}$.

A variety of theories have assumed that coherent discourse is structured by such implicit questions (e.g. Klein \& von Stutterheim 1987, van Kuppevelt 1994, Roberts 1995, Büring 2003), and focus on the answers to such explicit questions may well help the addressee to construct what the intended questions were. ${ }^{4}$ Under this understanding, all cases of so-called 'presentational' or 'information' focus which is claimed to express the most important part of the utterance, or what is new in the utterance, can be subsumed under the use of alternatives to indicate covert questions suggested by the context. The following examples suggest questions like What happened?, What was there?, and What did she $d o$ ?, which explains the types of foci suggested for the second clauses.

(13) a. And then something strange happened. [A MEterorite fell down $]_{\mathrm{F}}$.

b. Once upon a time, there was [a PRINcess $]_{F}$.

c. Mary sat down at her desk. She [took out a pile of NOTES $]_{F}$.

Other pragmatic uses of focus are to correct and confirm information. In cases like $\left(14 . \mathrm{B}^{\mathrm{B}} \mathrm{B}^{\prime}\right)$ the focus alternatives must include a proposition that has been proposed in the immediately preceding CG. It is expressed that among the alternatives the ordinary meaning is the only one that holds. This leads to a corrective interpretation in case the context proposition differed, cf. (B), and to a confirmative interpretation in case the context proposition was the same, cf. (B').

4 It should be stressed that we should not expect this use of focus to be universal; just as some languages use gender information to express pronoun binding and others do not, the use of focus to mark Q/A-coherence may be restricted. Findings about languages such as Hausa (Hartmann \& Zimmermann, to appear) and Northern Sotho (Zerbian 2006) suggest that this is the case. 
In the latter case, the wider CG must be such that other alternatives are under consideration as well, which are then excluded. Again, focus in this use restricts the possible contexts, and presumably aids interpretation.
A: Mary stole the cookie.
B: $($ No, $)[\text { PEter }]_{\mathrm{F}}$ stole the cookie!
$\mathrm{B}^{\prime}$ : Yes, $[\mathrm{MAry}]_{\mathrm{F}}$ stole the cookie.

Another pragmatic use of focus is in highlighting parallels in interpretations. This can affect whole clauses as in (15.a) or parts of clauses as in (b). As in the previous cases, focus creates alternatives, with the pragmatic requirement that some of these alternatives are also evoked in the immediately surrounding contexts. In addition, the parallel expressions are required to have the same set of alternatives. In the case of (15.a), both clauses evoke the set $\{\operatorname{STOLE}(x)(y) \mid x, y \in$ ENTITY . In the case of (b), the alternatives have to be constructed more locally, for which Rooth (1992) introduces an anaphoric operator C, which would presumably figure at the level of the NP or DP here. The NP-level alternatives are $\{\mathrm{P}(\mathrm{FARMER}) \mid \mathrm{P} \in$ NATIONALITY $\}$, a set of predicates like AMERICAN(FARMER), CANADIAN(FARMER), etc.

(15) a. MAry stole the COOkie and PEter stole the CHOcolate.

b. An AMErican farmer talked to a CaNAdian farmer,...

The use of focus to express parallel structures is perhaps one of the least understood aspects of focus. Focus appears to be less obligatory here than in the other cases. Presumably focus assists in constructing mental models of the described scene by associating the contrasted meanings.

Yet another pragmatic use of focus is to make the addressee aware of a delimitation of the utterance to the constituent in focus. This use subsumes, in 
particular, cases of contrastive topics such as John in I will come back to this in section 6.2 .

(16.a), but also focus in frame setting expressions as in (b). I will come back to this in section 6.2.

(16) a. As for JOHN, he was seen in the KITchen.

b. In MY opinion, JOHN stole the cookies.

With these types (answers, including selections from a list of items specified in the question, corrections, confirmations, parallels, and delimitation) we have covered the main pragmatic uses of focus. We turn to those uses of focus that have an immediate truth-conditional effect, that is, that directly influence CG content.

\subsection{Semantic uses of focus}

We say that semantic operators whose interpretational effects depend on focus are associated with focus. The best-known cases are focus-sensitive particles like only, also and even. There exists a variety of theories for the meaning of such particles, but they generally resort to the notion of alternatives, which, as we have seen above, also is central for the pragmatic uses of focus. In the case of exclusive particles like only, it is stated that the focus denotation is the only one among the alternatives that leads to a true assertion; additive particles like also express the presupposition that the assertion holds for other alternatives; and scalar particles like even presuppose that the denotation of the focus constituent is extreme when compared to other alternatives (cf. e.g. Jacobs 1983, König 1991).

But do these particles indeed affect the truth-conditional meaning? It is interesting to note that the focus information of additive and scalar particles does 
not affect the output $\mathrm{CG}$, but rather restricts the input $\mathrm{CG}$, as the alternatives are used to impose presuppositions. In particular, additive particles are close to a use within CG management, as they indicate that a proposition with an alternative to the item in focus had been expressed before or is part of the CG.

(17) $[\mathrm{JOHN}]_{\mathrm{F}}$ stole a cookie, and $[\mathrm{PEter}]_{\mathrm{F}}, \mathrm{TOO},{ }^{5}$ stole a cookie.

Negation has been analyzed as a focus-sensitive particle as well. Presumably these cases can be subsumed under corrections, and hence they might rather belong to the CG management use of focus. In the following example, it is negated that Bill stole the cookie, with the contextual requirement that precisely this has been claimed or appears to be inferable.

(18) Not $[\mathrm{BILL}]_{\mathrm{F}}$ stole the cookie, but $[\mathrm{JOHN}]_{\mathrm{F}}$.

But there are a number of clear cases in which alternatives are used for semantic purposes. For example, reason clauses as in (19), a variation of a counterfactual example of Dretske (1972), or operators like fortunately necessarily contrast alternatives with each other.

(19) $\left\{\begin{array}{l}\text { Clyde had to marry [BERtha }]_{F} \\ \text { Clyde had to }[\text { MARry }]_{F} \text { Bertha }\end{array}\right\} \begin{aligned} & \text { in order to be eligible. } \\ & \text { for the inheritance. }\end{aligned}$

(20) Fortunately, Bill spilled $[\text { WHITE }]_{\mathrm{F}}$ wine on the carpet.

For example, (20) says that among the two alternatives, JOHN SPILLED RED WINE and JOHN SPILLED WHITE WINE, the latter one was more fortunate (but of course that wine was spilled at all was still unfortunate).

5 As for a theory that explains accent on too, cf. Krifka (1999). 
Rooth (1985) has suggested that focus helps in determining the restrictor of quantifiers, in particular adverbial quantifiers, and then has truth-conditional impact as well. For example, focus has truth-conditional impact in (21); focus on $q$ instead would result in the different, and false, reading that every $\mathrm{u}$ is followed by a q.

(21) In English orthography, a $[\mathrm{U}]_{\mathrm{F}}$ always follows a q.

'Whenever a q follows an $\{a, b, c, d, \ldots z\}$, then it follows a u.'

One important fact about focus-sensitive operators is that they have to be in a position in which they can scope over their focus. For example, only in (22) could associate with Mary, with Sue, with introduced or with the whole VP, but not with John as it does not c-command John on any level of representation.

John only introduced Mary to Sue.

Yet it should be stressed that the notion of focus does not coincide with the notion of scope. For example, while the focus of only in (23.a) and (b) is the same, their scopes differ, leading to distinct interpretations.

(23)a. Mary only said that JOHN stole a cookie.

'Mary didn't say of anyone but John that he stole a cookie.'

b. Mary said that only JOHN stole a cookie.

'Mary said that nobody but John stole a cookie.'

It is conceivable that semantic uses of focus can be traced back to pragmatic uses. The underlying idea is as follows: The notion of alternatives to what is said was first introduced for pragmatic purposes, to convey additional meanings by making explicit that certain expressions were considered but not uttered, presumably because they were false or not informative enough. Once established, 
alternatives were used for operators that, due to their meaning, required reference to sets of denotations. In some cases, like additive particles and contrastive negation, this change from pragmatic exploitation of alternatives to semantic exploitation appears to be quite plausible; in other cases, as in (20) and (21), the details of such a development are considerably less clear. Such change from pragmatics to semantics is a common phenomenon that can be observed in the development of word meaning (cf. Levinson 2000 for pragmatically induced changes) and the semantization of implicatures (cf. Chierchia 2004).

It might be suggestive to distinguish between pragmatic and semantic focus by stating that the latter type of focus associates with an operator, while the former does not. But then we can assume illocutionary operators such as assertion or denial that make use of the alternatives introduced by focus, and we can say that focus is bound to such operators (cf. Jacobs 1984), hence this is not a valid criterion to distinguish between pragmatic and semantic uses.

\subsection{Comparison with alternative notions of focus}

The notion of focus has been explicated in a variety of ways, in particular as 'highlighting' the 'most important' or 'new' information in an utterance. While such explications are intuitively appealing and may apply to a majority of cases, I consider them unsatisfactory as definitions. The notion of highlighting is a particularly unclear one that is hardly predictive as long as we do not have a worked-out theory of what highlighting is. I am also not aware of any workedout theory of communication that has made clear what 'importance' means, let alone one that has introduced a graded notion of importance. Even on an intuitive level, the notion of importance is difficult to apply. In which sense is John the most important part in (24)? Isn't it most important that someone else stole the cookie? 
(24) It wasn't JOHN who stole the cookie.

As for the third, the notion of 'newness' has been defended most often in quite different frameworks, ranging from Halliday's 'information focus' (cf. Halliday 1967) to the Prague school (Sgall et al. 1986) and to Jackendoff (1972). But it clearly gives us wrong predictions. There are many cases in which a constituent that refers to something previously mentioned is in focus. One might say that what is new in (25) is not John, or the expression John, but the information that John satisfies the description $x$ stole the cookie.

A: Who stole the cookie, John or Mary?

B: JOHN stole the cookie.

When Jackendoff (1972) defines as 'information focus' the information that is not shared by speaker and addressee, then we must say something like the following: It is shared information in (25) that John or Mary stole the cookie. The difference to what the sentence says, that John stole the cookie, is a more specific proposition. But not just any more specific proposition would do; it must be one that is more specific in a particular dimension, indicated by the focus. This leads to the idea that focus indicates an existential presupposition (cf. Geurts \& van der Sandt 2004). If we have a sentence with a focus $\left[\ldots \alpha_{F} \ldots\right]$ then this sentence comes with the presupposition $\exists \mathrm{x}[\ldots \mathrm{x} \ldots]$, where $\mathrm{x}$ replaces the denotation of $\alpha$ in the representation of the denotation of $\left[\ldots \alpha_{F} \ldots\right]$. For example, (24) and (25) presuppose that someone stole the cookie, and in many other types of uses of focus we plausibly can assume existence presuppositions. But existence presuppositions do not arise with every use of focus, as in the following examples:

(26) Not even $[\text { MAry }]_{F}$ managed to solve the problem. 
(27) A: Who, if anyone, has solved this problem?

$\mathrm{B}$ : $[\mathrm{NO} \text { one }]_{\mathrm{F}}$ solved this problem.

If focus indicates the presence of alternatives, as suggested here, we can see why the other explanations made sense to some degree. The focus denotation typically feels highlighted because it is contrasted with the other alternatives; the selection of this denotation over alternative ones is often felt to be the most important contribution in a sentence; and the selected alternative is often also new (not mentioned previously). Also, in many cases it is already established in the CG content that the proposition applies to one alternative, but it is still open to which one. But this does not mean that highlighting, importance, newness, or presupposition of existence should figure in the definition of focus. They are statistical correlatives, but not definitional features, of focus. Using them to define focus is similar to using the notion of definiteness to define subjects: The great majority of subjects in running text are definite, but in many languages indefinite subjects are allowed.

\subsection{Further focus types}

I have argued that focus in general indicates the presence of alternatives for interpretation. Subtypes of focus then all are variations of this underlying idea. We have distinguished between expression focus and denotation focus according to the nature of the items in focus, and we have distinguished between pragmatic focus and semantic focus according to the general ways in which focus-induced alternatives are used - whether they make a truth-conditional difference or not. There are a number of additional criteria that can be applied to classify either the kind of alternatives or their use.

Starting with the type of alternatives, we have seen that constituents of different sizes can be put into focus: whole sentences, subconstituents like VPs or DPs, parts of DPs like adjectives or demonstratives. Sometimes terms like 
broad and narrow focus are used (cf. Selkirk 1984, Lambrecht 1994), but it should be clear that these are imprecise terms that can only be applied when different focus alternatives are under discussion. The position of the accent is determined by rules of accent percolation (also known as 'focus projection'), which leads to well-known ambiguities of focus marking (cf. Gussenhoven 1983, 1992, Selkirk 1984, 1995). For example, if a transitive VP is in focus then accent is realized on the argument, which also would signal narrow focus on the argument. For denotation focus it holds that whatever is in focus must be a meaningful unit, as denotational focus contrasts different meanings. An extreme case is so-called verum focus, focus on the truth value of a sentence, which may be expressed by accenting an auxiliary (as in She DOES like broccoli). It is an interesting issue whether parts of words can be put in focus. Paul (1880) has proposed this for a word like fahren 'to move in a land-bound vehicle', where according to him it is possible that only the manner component is in focus, which is phonologically indistinguishable from focus on the whole denotation. I think that cases like this do not force us to lexical decomposition; we can also assume that the alternatives are restricted to denotations of verbs of locomotion like fahren, gehen, reiten. Another type of sublexical focus is illustrated in We only saw stalagMITES in the cave, no stalagTITES, where the accent highlights a part does not carry meaning. As Artstein (2005) argues, this can be explained by a principle stating that accent creates maximally distinct representations for the focus and its alternatives.

It sometimes happens that one operator makes use of a combination of foci, resulting in complex focus:

John only introduced BILL to SUE. 
This says: The only pair $\langle\mathrm{x}, \mathrm{y}\rangle$ such that John introduced $\mathrm{x}$ to $\mathrm{y}$ is $\langle\mathrm{BILL}, \mathrm{SUE}\rangle$. It cannot be reduced to single foci; in particular, the sentence means something different from the following:

(29) John only introduced BILL only to SUE.

(29) is a case of multiple focus, in which in one and the same sentence, one expression introduces alternatives that are exploited in one way, and another expression introduces alternatives that are exploited in a different way. (29) can be paraphrased as: The only $\mathrm{x}$ such that John introduced $\mathrm{x}$ to Sue and no one else is $\mathrm{x}=$ Bill. The first only scopes over the second, and this is reflected by focus marking: Accent on Bill is stronger than accent on Sue, in contrast to the complex focus case of (28), where both accents are felt to be equally strong.

Another distinction relating to types of alternatives concerns the issue of the size of the alternative set. Sometimes this set is limited to a few items, perhaps down to the minimal number of two, the item in focus and one alternative. This is often the case in corrections or contrasts, in polarity questions that expect a positive or a negative answer, or in answers to alternative questions or restricted constituent questions such as the following:

A: What do you want to drink, tea or coffee?

B: I want $[\text { TEA }]_{F}$.

At other times the alternative set is unrestricted, satisfying just the general condition that all the alternatives must be compatible with the focus in their semantic type. It is tempting to call focus with a limited set of alternatives contrastive (as suggested by Chafe 1976), but (30.B) doesn't seem to be more contrastive than an answer to the non-restricted question What do you want to 
drink? I would rather suggest to distinguish between closed alternatives and open alternatives, and talk about closed vs. open focus, when necessary.

The notion of contrastive focus I would like to restrict to focus used for truly contrastive purposes, which presupposes that the CG content contains a proposition with which the current utterance can be constructed, or that such a proposition can be accommodated (cf. Jacobs 1988). In (30), it is CG management, not $\mathrm{CG}$ content that contains such a proposition. The typical use of contrastive focus is corrective, but it can also be additive, as in A: John wants coffee. B: MAry wants coffee, TOO. There is evidence for particular marking strategies for contrastive focus like the use of particular syntactic positions or of special prosodic patterns, see e.g. Selkirk (2002), Molnár (2001), Gussenhoven (2004).

Another type of focus that refers to the specific interpretation of the alternative's contribution is exhaustive focus. It indicates that the focus denotation is the only one that leads to a true proposition, or rather more general: that the focus denotation is the logically strongest that does so. É. Kiss (1998) has pointed out that focus movement in Hungarian triggers this specific meaning, and it appears that cleft constructions in English trigger it as well:

It's $[\mathrm{JOHN} \text { and BILL }]_{\mathrm{F}}$ that stole a cookie.

This example says that nobody else but John and Bill stole a cookie. Consequently, exhaustive focus is not compatible with additive particles, like too. I do not see a good reason to introduce, in addition to exhaustive focus, the notion of identification focus that expresses an identity statement, as in The ones who stole a cookie are John and Bill.

As a final focus type I would like to mention scalar focus, also called emphatic focus. In this case, the alternatives are ordered, and the focus denota- 
tion often is the least or greatest element. Scalar particles like even or at least require scalar focus, as well as strong polarity items such as in [Wild HORses $]_{\mathrm{F}}$ wouldn't drag me there.

\subsection{Representation formats for focus}

There are a number of ways in which the alternatives introduced by focus can be represented within a formal framework of semantic interpretation. These representations are not independent of the possible interpretations of focus, and hence should be discussed here.

Alternative Semantics (Rooth 1985, 1992) assumes two levels of interpretation, the ordinary level and the level of alternatives. They are construed in parallel, and operators that exploit focus refer to both the ordinary meaning and the alternatives. The construction mechanism is particularly simple and incorporates the idea of focus introducing alternatives in a natural way, in the sense that it could not even represent anything else besides alternatives. The theory also predicts that focus-sensitive operators have to be in a position in which they can scope over their focus. ${ }^{6}$ However, Alternative Semantics has only limited means to express that two foci belong together, as in the case of complex focus, and it is insufficient in certain cases of multiple focus (cf. von Stechow 1990, Kratzer 1994, Krifka 2001). The reason is that in Alternative Semantics, the focus denotations are not directly accessible to focus-sensitive operators; the operators can only access the effects that the focus alternatives had on the meanings of expressions. The set of alternatives of the following example with a complex focus is a set of propositions:

6 This does not necessarily hold for the version of Rooth (1992), where focus is mediated via anaphoric relations. 
(32) [John introduced BILL $L_{\mathrm{F}}$ to $\left.\mathrm{SUE}_{\mathrm{F}}\right]$.

Meaning: INTRODUCED(BILL)(SUE)(JOHN)

Alternatives: $\{\operatorname{INTRODUCED}(\mathrm{x})(\mathrm{y})(\mathrm{JOHN}) \mid \mathrm{x}, \mathrm{y} \in \mathrm{D}\}$

$$
\begin{aligned}
= & \text { INTRODUCED(BILL)(SUE)(JOHN), } \\
& \text { INTRODUCED(BILL)(MARY)(JOHN), } \\
& \text { INTRODUCED(JIM)(SUE)(JOHN), } \\
& \text { INTRODUCED(JIM)(MARY)(JOHN), ... }\}
\end{aligned}
$$

The Structured Meaning approach to focus (von Stechow 1990, Krifka 1992) assumes that focusing leads to a partition of meanings into a focus part and a background part that, when applied to the focus denotation, yields the ordinary interpretation. Example (32) would get the following representation, where background and focus are represented by a pair, $\langle\mathrm{B}, \mathrm{F}\rangle$.

$$
\langle\lambda\langle\mathrm{x}, \mathrm{y}\rangle[\mathrm{INTRODUCED}(\mathrm{x})(\mathrm{y})(\mathrm{JOHN})],\langle\text { BILL, SUE }\rangle\rangle
$$

The notion of background corresponds to the one of presupposition skeleton of Jackendoff (1972); notice that there is no corresponding notion within Alternative Semantics. The structuring can be triggered by syntactic movement of the focus item, as overtly done in focus movement, or by some equivalent operation. The Structured Meaning representation can express multiple focus and complex focus, but the representation format is not particularly tied to the notion of alternatives. It has to be stipulated that focus-sensitive operators are only allowed to express operations that relate a focus denotation to its alternatives (cf. Rooth 1995, who discusses this problem with a hypothetical verbal predicate, tolfed).

There is another framework of focus representation, In-Situ Binding Semantics, as developed in Wold (1996), whose representational complexity lies in between Alternative Semantics and Structured Meanings. It does not allow direct access to the focus denotation, but has a notion of background that makes it 
possible to refer to the position in which foci are interpreted, and hence is able to express dependencies between foci.

It might well be that we need more than one representation format to cover different aspects of focus. In particular, we might argue that focus marked by overt movement into a cleft position or dedicated focus position should be captured by Structured Meanings as this reflects the syntactic structures involved and thus predicts certain syntactic island restrictions. It is an open debate whether cases of in-situ focus should to be modeled by covert movement on LF, as the Structured Meaning approach does. On the one hand, it was pointed out early on that syntactic island restrictions in association with focus phenomena appear to be lacking (cf. Jackendoff 1972); on the other hand, it has been argued that they are in fact present (Drubig 1994). The discussion revolves around examples of the following kind:

John didn't introduced Bill to [the woman he met at SUE's party] (but *MAry's / the woman he met at MAry's party).

It appears that the negation associates with focus on Sue, violating island restrictions. But then the but-phrase has to take up the whole constituent, not just the focus. This has been taken as evidence that the negation associates with the whole bracketed NP, not with Sue. We can distinguish between a focus phrase (here, the woman he met at SUE' $s_{\mathrm{F}}$ party) that contains a focus, which in turn determines the alternatives to the focus phrase. In the majority of cases, focus and focus phrase coincide, but not always, as (34) illustrates. As the focus can be deeply embedded within the focus phrase, this suggests a hybrid representation of focus: The relation between focus and focus phrase is mediated by the mechanisms of Alternative Semantics, and the relation between focus phrase and focus-sensitive operator is mediated by Structured Meanings (cf. Krifka 2006). 


\section{Givenness}

\subsection{What is Givenness?}

We now turn to the second important category of IS, the indication that the denotation of an expression is present in the immediate CG content. Givenness was prominently treated by Chafe (1976), and there is ample evidence that human languages have devices with which speakers can make addressees aware that something that is present in the immediate linguistic context is taken up again.

A definition of Givenness must be such that it allows us to say that an expression is given to a particular degree, e.g. whether it is maximally salient in the immediate CG or just given there, or whether it is given in the general CG or not given at all. The following attempt at a general definition accounts for that distinction.
A feature $X$ of an expression $\alpha$ is a Givenness feature iff $X$ indicates whether the denotation of $\alpha$ is present in the CG or not, and/or indi- cates the degree to which it is present in the immediate CG.

With Focus we distinguished between expression focus and denotation focus. We do not have to make this distinction here, as Givenness always refers to denotations, never to expressions. There are two groups of phenomena that refer to Givenness, namely specific anaphoric expressions that have givenness features as part of their lexical specification, and other grammatical devices such as deaccentuation, ordering and deletion that can mark arbitrary constituents as given. I will deal with them in turn.

\subsection{Anaphoric expressions}

These are specific linguistic forms that indicate the givenness status of their denotations, including personal pronouns, clitics and person inflection, demon- 
stratives, definite articles, but also indefinite articles that indicate that their referent is not given. Definite articles can be used to indicate whether a denotation is given in a $\mathrm{CG}$ in general, whereas clitics and pronouns typically indicate that their denotations are given in the immediate CG.

There is a large literature on anaphoric devices, which I cannot even start to do justice here. But I want to point out that speakers typically have a hierarchy of distinct linguistic means at their disposal (as zero forms, clitics, pronouns, demonstratives...), and that denotations in the immediate CG are ranked with respect to their givenness status such that simpler anaphoric expressions are used to refer to more salient denotations (cf. Prince 1981, Gundel et al. 1993). This insight has been implemented within Centering Theory, which has developed formal means to model the dynamic change of the saliency of discourse referents in communication (cf. papers in Walker et al. 1998).

\subsection{Deaccentuation, deletion and word order}

There are three other ways to indicate Givenness: Deaccentuation, the reduction of the prosodic realization of expressions that are given in the immediate context; deletion, which can be seen as an extreme form of reduction; and the realization of an expression in a non-canonical position, typically before the canonical position. This is illustrated in the following examples:

(36) a. Ten years after John inherited an old farm, he SOLD [the shed $]_{\text {Given. }}$.

b. Bill went to Greenland, and Mary did _too.

c. Bill showed the boy a girl.

* Bill showed a boy the girl.

Bill showed the girl to a boy. 
In the first example, which corresponds to examples used by Umbach (2003), the shed is deaccented, and has to be understood as referring to the farm mentioned before. If it were not deaccented, it would mean something different, like the shed that came with the farm. Example (b) illustrates VP ellipsis, which refers back to a VP meaning. The examples in (c) show that in the double object construction, given constituents precede constituents that are new. This is a rule with high functional load in so-called free word order languages, an insight that goes back to Weil (1844).

As focus constituents typically are not given, and are realized with greater prosodic prominence, it has been proposed that focus is a complementary notion to givenness so that the latter can ultimately be eliminated from theoretical terminology (cf. Daneš 1970, Sgall et al. 1986). But given constituents can be in focus, and then bear accent. For example, it is possible to focus on pronouns, as in Mary only saw $[H I M]_{\mathrm{F}}$. Schwarzschild (1999) develops a more refined theory of interaction between givenness and focusation, which checks givenness recursively and states that constituents not in focus must be given, and that focus has to be applied only when necessary, that is, to prevent that a constituent is given. But while focus is restricted in Schwarzschild's theory, it cannot be eliminated totally.

We have to assume both focus - the indication of alternatives, which is expressed by accentuation - and rules of marking given constituents, e.g. by deaccentuation. As the case of accented pronouns shows, focus accentuation overrides deaccentuation of given constituents, in the sense that focus has to be expressed by accent. However, if a larger constituent is focused, then givenness can influence the accent rules: The constituent that normally would bear accent can be deaccented, and accent can be realized on some other constituent within the focus expression (cf. Féry \& Samek-Lodovici 2006). For example, while in 
VP focus the accent is normally realized on the argument, it is realized on the head when the argument is given:
A: I know that John stole a cookie. What did he do then?
B: He [reTURNED [the cookie $\left.]_{\text {Given }}\right]_{\text {Focus }}$.

This suggests an explanation why accent is normally realized on the argument in cases of wide focus. It is the arguments, not the heads, that are referential, and therefore the need to express whether they refer to something given is more pressing. If the normal accentuation rules state that accent is realized on the argument, then givenness of arguments can be expressed by deaccenting the argument and accenting the head instead.

\section{Topics}

\subsection{What is Topic?}

The terms 'topic' and 'comment' are used most frequently to refer to what has been introduced into linguistic thinking as 'psychological subject' and 'psychological predicate' by von der Gabelentz (1869), who used the first term to refer to the object which the speaker is thinking about, and the second to refer to what the speaker is thinking about it. In terms related more closely to communication, topic is the entity that a speaker identifies about which then information, the comment, is given. This presupposes that information in human communication and memory is organized in a certain way so that it can be said to be 'about' something. This does not follow from a general definition of information. For example, relational databases or sets of possible worlds, both models for information, do not presuppose any relation of aboutness.

Reinhart (1982) has integrated this notion of topic into a theory of communication that makes use of the notion of CG. According to her, new 
information is not just added to the CG content in form of unstructured propositions, but is rather associated with entities, just like information in a file card system is associated with file cards that bear a particular heading. For example, while $(38 . a, b)$ express the same proposition, they structure it differently insofar as (a) should be stored as information about Aristotle Onassis, whereas (b) should be stored as information about Jacqueline Kennedy.

(38) a. [Aristotle Onassis $]_{\text {Topic }}[\text { married Jacqueline Kennedy }]_{\text {Comment. }}$

b. [Jacqueline Kennedy $]_{\text {Topic }}[\text { married Aristotle Onassis }]_{\text {Comment }}$.

This leads to the following definition, which presupposes a file-card like structure of information storage.

\section{The topic constituent identifies the entity or set of entities under which the information expressed in the comment constituent should be stored in the CG content.}

Just as with the notion of 'focus', the notion of 'topic' has not been used in a terminologically clean way. Chafe (1976) called what is defined in (39) 'subject', a term that should be reserved for grammatical subjects to avoid confusion. Vallduví (1992) and Vallduví \& Engdahl (1996) have used the term 'link'. In the Prague School, the notion of topic is called 'theme', and conflated with the one of old information (e.g., Daneš 1970). We should refrain from this, even if in many cases, topic constituents are 'old' in the sense of being inferable from the context. But there are certainly cases of new topics. The following sentence introduces a new entity into discourse and, at the same time, uses it as the denotation of a topic constituent, which amounts to introducing a new file card in the CG content. 
(40) $[\text { A good friend of mine }]_{\text {Topic }}[\text { married Britney Spears last year }]_{\text {Comment. }}$

The notions of Topic/Comment are sometimes mixed up with the notions of Background/Focus. However, as we will see in section 5.2, there are topics that contain a focus. And the Comment need not be identical to the focus either:

(41) A: When did [Aristotle Onassis $]_{\text {Topic }}$ marry Jacqueline Kennedy?

B: $\left.\left.[\mathrm{He}]_{\text {Topic }}[\text { married her [in 1968 }]_{\text {Focus }}\right]\right]_{\text {Comment }}$.

The definition in (39) includes the option that a comment is made about a set of entities. This accounts for the typical way quantified sentences are interpreted, in which two sets are related by a quantifier that can be realized as a determiner or as an adverbial:

(42) a. Every zebra in the zoo was sick.

b. Most zebras in the zoo were sick.

(43) Zebras in the zoo usually are sick.

The quantifier in such sentences expresses the extent to which the comment holds for the elements of the set. Assuming that sentences like (42), (43) are about zebras explains why natural language quantifiers are conservative, that is, why the truth value of sentences that contain a quantifier can be checked by looking solely at the restrictor set (here the set of zebras). It is important to note that the restrictor of quantifiers is not always topical, but in the majority of cases it is, and the property of conservativity that is motivated in those cases is transferred to cases in which quantifiers are not topical.

Sentences typically have only one topic, which can be explained within Reinhart's file-card metaphor: The simplest way to add information is to add it on one file card. But sentences with two or more topics are possible under cer- 
tain circumstances, in case a relation between two file cards is expressed, as in As for Jack and Jill, they married last year. A possible way to handle such cases is to introduce a new file card that contains information concerning both Jack and Jill. On the other hand, sentences may have no topic constituent at all, under which condition they are called thetic, following Marty (1884). But as already Marty had indicated, this does not mean that such sentences are about nothing. While they lack a topic constituent, they do have a topic denotation, typically a situation that is given in the context, as in [The HOUSE is on fire $]_{\text {Comment }}$

In addition to the notion topic/comment, some theories also assume a structuring into subject and predicate, or predication basis and predicate, cf. Sasse (1987), Jacobs (2001) and Kuroda (2005). I will not go into this distinction here in greater detail, but I doubt that it is a distinction that is to be explained as one of IS.

But then the question is whether topic and comment should be considered terms relating to IS at all. Without question, topic/comment structure is a packaging phenomenon; (38.a) and (b) package the same information differently, so that it is entered on the file card for Aristotle Onassis and for Jacqueline Kennedy, respectively. But section 2.1 stressed that the packaging must respond to the temporary (recent) common ground, and this restriction certainly is not always satisfied. Assume that two speakers A, B meet who both know John well, and A says to B: Did you know? John has married last week. This is an assertion about John; the information will be entered in the file card for John in the CG content of A and $\mathrm{B}$. But this does not necessarily relate to the recent state of the CG content, it can also respond to the long-term state, e.g. a long established and known interest of B in John.

Yet we find that topic choice often does respond to properties of the temporary information state. There is a well-documented tendency to keep the topic constant over longer stretches of discourse (so-called topic chains, cf. Givón 
1983). Hence, while the notions of topic and comment fail to be IS terms in the sense that they always relate to the temporary state of the CG, they do quite often do relate to it, as the topic denotation in the preceding utterance is the first choice for the topic denotation of the present utterance.

\subsection{Contrastive Topics}

Contrastive topics are topics with a rising accent, as in B's answer in (44). They arguably do not constitute an information-packaging category in their own right, but represent a combination of topic and focus, as indicated in the example, in the following sense: They consist of an aboutness topic that contains a focus, which is doing what focus always does, namely indicating an alternative. In this case, it indicates an alternative aboutness topics.
A: What do your siblings do?
B: $\left[\mathrm{My}[\mathrm{SISter}]_{\text {Focus }}\right]_{\text {Topic }}[\text { studies MEDicine }]_{\text {Focus }}$, and [my [BROther $\left.]_{\text {Focus }}\right]_{\text {Topic }}$ is [working on a FREIGHT ship $]_{\text {Focus. }}$

In the first clause of B's response, focus on sister indicates an alternative to the topic 'my sister', namely, 'my brother'. The typical reason why the presence of an alternative is highlighted is to indicate that the present clause does not deliver all the information that is expected. This is why we often find contrastive topics to indicate a strategy of incremental answering in the CG management, as in our example in which an issue is split into sub-issues. This has been assumed to be the function of contrastive topics in Roberts (1996) and Büring (1997, 2003). It is pointed out in this literature that there are accommodation phenomena that affect what we call CG management. In the following case, contrastive topic accommodates a more general question, Who was where?
A: Where were you (at the time of the murder)?
B: $\left[[\mathrm{I}]_{\text {Focus }}\right]_{\text {Topic }}\left[\text { was }[\text { at HOME }]_{\text {Focus }}\right]_{\text {Comment }}$. 
However, it should be noted that we find contrastive topics also in cases in which the idea of a questioning strategy is not easily applicable. In example (46) the answer given does not satisfy the expectations expressed in the question, in combination with a rising intonation in the comment that indicates that the assertion, while being the best one to be made, may not satisfy all needs.
A: Does your sister speak Portuguese?
B: $\left[\mathrm{My}[\text { BROther }]_{\text {Focus }}\right]_{\text {Topic }}\left[[\mathrm{DOES}]_{\text {Focus }}\right]_{\text {Comment }}$.

It should be noted that focus within a topic is interpreted as usual: indicating the presence of alternatives, in this case, alternative topics. Focus is marked by (rising) accent, but it is not the main accent of the sentence, which is on a constituent of the comment.

\section{Frame Setting and Delimitation}

\subsection{What is frame setting?}

Frame setting, according to Jacobs (2001), is often not separated clearly from aboutness topic, and Chafe (1976), who stresses their difference, uses the term 'topic' for precisely this function. What is it? Statements like (47) certainly should not be entered under a file card about the health situation, and the topic of (48) is Daimler-Chrysler, not Germany or America.

(47) A: How is John?

B: $\{$ Healthwise / As for his health $\}$, he is $[\mathrm{FINE}]_{\text {Focus }}$.

(48) A: How is business going for Daimler-Chrysler?

B: $[\text { In GERmany }]_{\text {Frame }}$ the prospects are $[\mathrm{GOOD}]_{\text {Focus }}$, but $[\text { in AMErica }]_{\text {Frame }}$ they are $[\text { losing MOney }]_{\text {Focus. }}$. 
It is often said that adverbials like healthwise or in Germany are frame setters that set the frame in which the following expression should be interpreted; According to Chafe, frame setting is used "to limit the applicability of the main predication to a certain restricted domain". It is still unclear how this should be understood more precisely. For cases like (47) which contain an evaluative predicate (fine) that is unspecified with respect to the dimension of evaluation (financially, healthwise, spiritually etc.), this can be rendered more precisely by assuming that it is the task of the frame-setting adverbial to specify that dimension. Similarly, (48) has a situation dimension that is specified by the frame setter. But we also have statements like As for his health situation, he had a bypass operation recently, which cannot be explained in this way. It appears that frame setters indicate the general type of information that can be given about an individual. A possible implementation of this idea is that they systematically restrict the language (the notions that can be expressed) in certain ways: notions like he won a lot of money cannot be interpreted in the scope of healthwise, and notions like he is doing fine have to be restricted to the indicated dimension.

In any case, in dialogues like (47) alternative frames play a role, and hence we can assume that explicit frame setters always are focused in the sense of section 3.1. They choose one out of a set of frames and state that the proposition holds within this frame. If there is no alternative perspective to be considered, then there is no need for an explicit frame setter either. As explicit frame setters always indicate alternatives, they clearly belong to IS. More specifically, they relate to CG management, as they imply that there are other aspects for which other predications might hold. In this they are similar to contrastive topics (section 5.2), as they too split up a complex issue into sub-issues. 


\subsection{Delimitation}

The similarity between contrastive topics and frame setters mentioned above is worth to be looked at more closely. What contrastive topics and frame setters have in common is that they express that, for the communicative needs at the current point of discourse, the present contribution only gives a limited or incomplete answer. In the case of contrastive topics, the current CG management contains the expectation that information about a more comprehensive, or distinct, entity is given; contrastive topic indicates that the topic of the sentence diverges from this expectation. With frame setters, the current CG management contains the expectation that information of a different, e.g. more comprehensive, type is given, and the frame setter indicates that the information actually provided is restricted to the particular dimension specified. This more general view is suggested in Büring's notion of contrastive topics, which do not have to be topics in the sense of aboutness topics.

Büring develops a formal model of this notion within the representation framework of Alternative Semantics: The contrastive topic induces a set of alternatives over and above the set of alternatives that are introduced by the focus within the predication, ending up with sets of sets of alternatives.

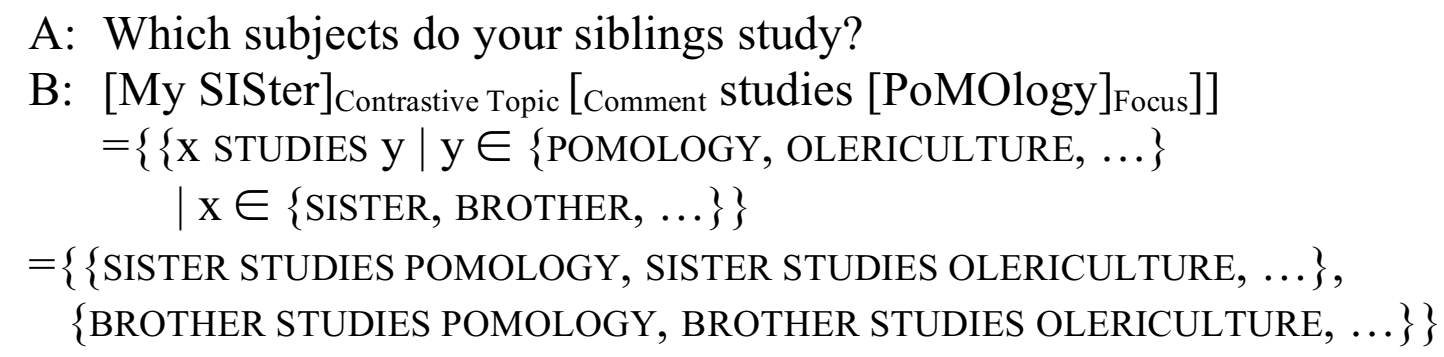

This incorporates the important observation that contrastive topics always occur in expressions that have another focus outside of the contrastive topic, a rule that holds for frame setters as well. But one should distinguish the formal implemen- 
tation of delimitation from its communicative purpose. The following is an attempt to characterize this in a most general way:

(50) A Delimitator $\alpha$ in an expression $\left[\ldots \alpha \ldots \beta_{\text {Focus } \ldots]}\right.$ always comes with a focus within $\alpha$ that generates alternatives $\alpha^{\prime}$. It indicates that the current informational needs of the $C G$ are not wholly satisfied by $\left[\ldots \alpha \ldots \beta_{\text {Focus }} ..\right]$, but would be satisfied by additional expressions of the general form $\left[\ldots \alpha^{\prime} \ldots \beta^{\prime}{ }_{\text {Focus }} ..\right]$.

In this definition, no reference to (aboutness) topic or frame setting is made. This allows for cases like (51) that do not plausibly belong to either category:

$$
[\text { An [inGEnious }] \text { mathematician }]_{\text {Delim }} \text { he is }[\mathrm{NOT}]_{\text {Focus }} \text {. }
$$

The sentence suggests alternative statements like He is a mediocre mathematician hold. The definition in (50) is also neutral as to the speech act type of the expression, which explains why delimitations occur in questions and commands as in (52):

(52) And when did you read [DostoYEVsky $]_{\text {Delim }}$ in school?

Delimitation indicates that the respective question does not express the full communicative needs as there are other questions at issue, such as When did you read Shakespeare in school?

If delimitations do what they are suggested to do here, then this explains why they often help to indicate a certain questioning strategy. If it is explicitly marked that an expression is suboptimal as far as the communicative needs of the moment are concerned, then one important reason for this is that the current communicative move only responds to a local need, and not yet to the global need of the CG. By this they help to structure CG management by distinguishing between local and more global communicative goals. 


\section{Cohesion and rhetorical structure}

The notion of a structured set of questions under discussion that has been developed by a variety of researchers, such as Klein \& von Stutterheim (1987), van Kuppevelt (1994), Roberts (1996) and Büring (2003), leads to a richer understanding of CG management. We have seen that delimiters can create and respond to such structures.

I would like to point out that beyond the idea of question stacks and question trees, linguistic communication is built on a rich structure of discourse relations, as investigated in a number of theories such as in the study of cohesion in Halliday \& Hasan (1976), and in Rhetorical Structure Theory (Mann \& Thompson 1988). Structured Discourse Representation Theory, as developed in Asher \& Lascarides (2004), shows that there is an interaction between discourse structure and possible anaphoric relations. CG management cannot be described without referring to the strategies used to narrate events or make arguments. For example, there are strategies that first lay out the premises and then lead to a conclusion, and there are others that start with the conclusion and then motivate it or elaborate on it. This will result in locally distinct structures of the CG, and each individual sentence will respond to those. In this sense, the devices studied in these theories, like discourse particles and intonational meaning, squarely belong to Information Structure as envisioned by Chafe.

\section{Reference}

Artstein, Ron (2005) Quantificational arguments in temporal adjunct clauses. Linguistics and Philosophy 28(5), 541-597.

Asher, Nicholas \& Alex Lascarides (2004), Logics of conversation, Cambridge University Press, Cambridge.

Büring, Daniel (1997), The 59th Street Bridge Accent, Routledge, London. 
Büring, Daniel (2003), "On D-trees, beans, and B-accents", Linguistics and Philosophy 26, 511-545.

Chafe, Wallace L. (1976), "Givenness, contrastiveness, definiteness, subjects, topics and point of view", in Charles N. Li (ed.), Subject and Topic, Academic Press, New York, 27-55.

Chierchia, Gennaro (2004), "Scalar implicature, polarity phenomena, and the syntax/pragmatics interface", in Adriana Belletti (ed.), Structures and Beyond, Oxford University Press, Oxford.

Clark, Herbert H. (1996), Using language, Cambridge University Press, Cambridge.

Daneš, Frantisek (1970), "One instance of the Prague school methodology: Functional analysis of utterance and text", in Paul L. Garvin (ed.), Method and theory in linguistics, Mouton, Paris, The Hague, 132-146.

Dretske, Fred (1972), “Contrastive statements", Philosophical Review 81, 411437.

Drubig, Hans Bernhard (1994), Island constraints and the syntactic nature of focus and association with focus, (Arbeitspapiere des Sonderforschungsbereichs 340, Nr. 51). Tübingen.

Féry, Caroline \& Vieri Samek-Lodovici (2006), "Discussion notes: Focus projection and prosodic prominence in nested foci", Language 82, 131-150.

Geurts, Bart \& Rob van der Sandt (2004), "Interpreting focus", Theoretical Linguistics 30, 1-44.

Givón, Talmy (1983), Topic Continuity in Discourse: A Quantitative CrossLanguage Study, John Benjamins, Amsterdam.

Groenendijk, Jeroen (1999), "The logic of interrogation", Semantics and Linguistic Theory (SALT) IX. CLC Publications, Ithaca, 109-126.

Gundel, Jeanette K., Nancy Hedberg \& Ron Zacharski (1993), "Cognitive status and the form of referring expressions in discourse", Language 69, 274-307.

Gussenhoven, Carlos (1983), "Focus, mode, and the nucleus", Journal of Linguistics 19, 377-417. 
Gussenhoven, Carlos (1992), "Sentence accents and argument structure", in Iggy M. Roca (ed.), Thematic structure. Its role in grammar, Foris, Berlin, New York, 79-106.

Gussenhoven, Carlos (2004), The phonology of tone and intonation, Cambridge University Press, Cambridge.

Halliday, Michael A. K. \& Ruqaiya Hasan (1976), Cohesion in English, Longman, London.

Halliday, Michael A. K. (1967), Intonation and Grammar in British English, Mouton, The Hague.

Hamblin, Charles Leonard (1973), "Questions in Montague English", Foundations of Language 10, 41-53.

Hartmann, Katharina \& Malte Zimmermann (to appear), "In place - out of place: Focus in Hausa", in Kerstin Schwabe \& Susanne Winkler (eds.), On information structure, meaning and form, John Benjamins, Amsterdam.

Heim, Irene (1982), The Semantics of Definite and Indefinite Noun Phrases, Diss., University of Massachusetts,Amherst.

Horn, Laurence R. (1985), "Metalinguistic negation and pragmatic ambiguity", Language 61, 121-174.

Hutchby, Ian \& Robin Wooffitt (1988), Conversation analysis, Polity Press.

Jackendoff, Ray (1972), Semantic Interpretation in Generative Grammar, MIT Press, Cambridge.

Jacobs, Joachim (1983), Fokus und Skalen, Niemeyer, Tübingen.

Jacobs, Joachim (1984), "Funktionale Satzperspektive und Illokutionssemantik", Linguistische Berichte 91, 25-58.

Jacobs, Joachim (1988), "Fokus-Hintergrund-Gliederung und Grammatik", in Hans Altmann (ed.), Intonationsforschungen, Tübingen, Niemeyer, 89134.

Jacobs, Joachim (2001), "The dimensions of topic-comment", Linguistics 39, 641-681.

Kamp, Hans (1981), "A theory of truth and semantic representation", in Jeroen A.G. Groenendijk, Theo M.V. Janssen \& Martin B.J. Stokhof (eds.), For- 
mal Methods in the Study of Language, (Mathematical Centre Tracts 135), Mathematical Centre, Amsterdam, 277-322.

Karttunen, Lauri (1974), "Presuppositions and linguistic context", Theoretical Linguistics 1, 181-194.

É. Kiss, Katalin (1998), "Identificational focus versus information focus", Language 74, 245-273.

Klein, Wolfgang \& Christiane von Stutterheim (1987), "Quaestio und referentielle Bewegung in Erzählungen", Linguistische Berichte 109, 163-183.

König, Ekkehart (1991), The meaning of focus particles. A comparative perspective, Routledge, London, New York.

Kratzer, Angelika (1994), "The representation of focus", in Arnim von Stechow \& Dieter Wunderlich (eds.), Handbook of Semantics, de Gruyter, Berlin, 825-834.

Krifka, Manfred (1992), "A compositional semantics for multiple focus constructions", in Joachim Jacobs (ed.), Informationsstruktur und Grammatik, Westdeutscher Verlag, Opladen, 17-53.

Krifka, Manfred (1999), "Additive particles under stress", Semantics and Linguistic Theory (SALT) IIX. CLC Publications, Ithaca, 111-128.

Krifka, Manfred (2001), "For a structured account of questions and answers", in Caroline Féry \& Wolfgang Sternefeld (eds.), Audiatur vox sapientiae. A Festschrift for Arnim von Stechow, Akademie-Verlag, Berlin, 287-319.

Krifka, Manfred (2006), "Association with focus phrases", in Valerie Molnár \& Susanne Winkler (eds.), The architecture of focus, Mouton de Gruyter, Berlin, 105-136.

Kuroda, Sige-Yuki (2005), "Focusing on the matter of topic. A study of wa and ga in Japanese", Journal of East Asian Linguistics 14, 1-58.

Lambrecht, Knud (1994), Information structure and sentence form. Topic, focus, and the mental representation of discourse referents, Cambridge University Press, Cambridge.

Levinson, Stephen C. (2000), Presumptive meanings, MIT Press, Cambridge.

Lewis, David (1979), "Scorekeeping in a language game", Journal of Philosophical Logic 8, 339-359. 
Mann, William C. \& Sandra A. Thompson (1988), "Rhetorical structure theory. Towards a theory of text organization", Text 8, 243-281.

Marty, Anton (1884), "Über subjektlose Sätze und das Verhältnis der Grammatik zu Logik und Psychologie", Vierteljahresschrift für wissenschaftliche Philosophie 8, 161-192 und 292-340.

Merin, Arthur (1994), "Algebra of elementary social acts", in Savas L. Tsohatzidis (ed.), Foundations of speech act theory. Philosophical and linguistic perspectives, Routledge, London, 234-266.

Molnár, Valéria (2001), "Contrast from a contrastive perspective", in Ivana Kruiff-Korbayová \& Mark Steedman (eds.), Proceedings of the ESSLLI 2001 Workshop on Information Structure, Discourse Structure and Discourse Semantics, Helsinki University, Helsinki, 99-114.

Paul, Hermann (1880), Principien der Sprachgeschichte, Niemeyer, Halle.

Prince, Ellen (1981), "Towards a taxonomy of given-new information", in Peter Cole (ed.), Radical Pragmatics, Academic Press, New York, 223-256.

Reinhart, Tanya (1982), "Pragmatics and linguistics. An analysis of sentence topics", Philosophica 27, 53-94.

Roberts, Craige (1996), "Information structure in discourse: Towards an integrated formal theory of pragmatics", in Jae Hak Yoon \& Andreas Kathol (eds.), OSU Working Papers in Linguistics 49: Papers in Semantics, The Ohio State University, Columbus, 91-136.

Rooth, Mats (1985), Association with Focus, Diss., University of Massachusetts, Amherst.

Rooth, Mats (1992), “A theory of focus interpretation", Natural Language Semantics $1,75-116$.

Rooth, Mats (1995), "Indefinites, Adverbs of Quantification, and Focus Semantics", in Gregory N. Carlson \& Francis J. Pelletier (eds.), The Generic Book. The Universtity of Chicago Press, Chicago, 265-299.

Sasse, Hans-Jürgen (1987), "The thetic/categorical distinction revisited", Linguistics 25, 511-580.

Schwarzschild, Roger (1999), "GIVENness, AvoidF and other constraints on the placement of accent”, Natural Language Semantics 7, 141-177. 
Selkirk, Elisabeth O. (1984), Phonology and syntax: The relation between sound and structure, MIT Press, Cambridge.

Selkirk, Elisabeth O. (1995), "Sentence prosody: Intonation, stress and phrasing", in John Goldsmith (ed.), Handbook of phonological theory, Blackwell, Cambridge, 550-569.

Selkirk, Elisabeth O. (2002), "Contrastive FOCUS vs. presentational focus: Prosodic evidence from right node raising in English", Speech Prosody 2002: Proceedings of the First International Speech Prosody Conference, Laboratoire Parole et Langage, Aix-en-Provence, 643-646.

Sgall, Petr, Eva Hajicova \& Jarmila Panenova (1986), The meaning of the sentence and its semantic and pragmatic aspects, Reidel, Dordrecht.

Stalnaker, Robert (1974), "Pragmatic presuppositions", in Milton K. Munitz \& Peter K. Unger (eds.), Semantics and Philosophy, New York University Press, New York, 197-214.

Umbach, Carla (2004), "Cataphoric indefinites", Proceedings of Sinn und Bedeutung VIII, Konstanz Linguistics Working Papers, University of Konstanz, Konstanz 301-316.

Vallduví, Enrique \& Elisabet Engdahl (1996), "The linguistic realization of information packaging", Linguistics 34, 459-519.

Vallduví, Enrique (1992), The informational component, Garland, New York.

van der Sandt, Rob A. (1988), Context and presupposition, Croom Helm, London.

van Kuppevelt, Jan (1994), “Topic and comment”, in Ronald E. Asher (ed.), The Encyclopedia of Language and Linguistics, Pergamon Press, Oxford, 4629-4633.

von der Gabelentz, Georg (1869), "Ideen zu einer vergleichenden Syntax", Zeitschrift fur Völkerpsychologie und Sprachwissenschaft 6, 376-384.

von Stechow, Arnim (1990), "Focusing and backgrounding operators", in Werner Abraham (ed.), Discourse particles, John Benjamins, Amsterdam, 3784.

Walker, Marilyn, Aravind K. Joshi \& Ellen Prince (eds.) (1998), Centering Theory in Discourse, Clarendon Press, Oxford. 
Weil, Henri (1844), De l'ordre des mots dans les langues anciennes comparées aux langues modernes, Didier Érudition, Paris.

Wold, Dag (1996), "Long distance selective binding: The case of focus", Proceedings of SALT VI, CLC Publications, Ithaca, 311-328.

Zerbian, Sabine (2006), Expression of Information Structure in the Bantu Language Northern Sotho, Diss., Humboldt University, Berlin.

Manfred Krifka

Humboldt Universität zu Berlin

and Zentrum für Allgemeine Sprachwissenschaft (ZAS) Berlin

Unter den Linden 6

10099 Berlin

Germany

krifka@rz.hu-berlin.de

http://amor.rz.hu-berlin.de/ h2816i3x 
